\title{
Vigencia de la norma y protección de bienes jurídicos ${ }^{*}$
}

Urs Kindhäuser ${ }^{1}$

1. De conformidad con el principio de ultima ratio, la pena es una reacción estatal cuyo empleo solo es legítimo cuando otros medios fracasan. El objetivo, en virtud de cuya realización se evalúa la eficiencia de los correspondientes medios en disputa, es, según opinión general, la protección de bienes jurídicos. Sin embargo, esta opinión reduce arbitrariamente la clase de tarea propia del derecho penal y dificulta, a raíz de esta reducción, una justificación racional de la pena. Mi tesis, la cual será fundamentada a grandes rasgos en las líneas que siguen, reza así: la pena solo puede servir y de hecho solo sirve- indirectamente a la protección de bienes jurídicos. El objetivo inmediato de la protección jurídico penal es el bien jurídico penal ${ }^{2}$, es decir, un nivel suficiente de motivación fiel al derecho. El bien jurídico penal facilita la protección de bienes jurídicos en la medida en que el punto de referencia de la motivación es el reconocimiento efectivo, como razón para la acción, de normas que protegen bienes jurídicos.

Si la pena se legitima (inmediatamente) a través de la garantía del bien jurídico penal, entonces ello presupone que no solo es legítimo el mal de la pena, sino que también lo es el reproche ético jurídico constitutivo del concepto de pena. Solo es legítimo lo que es justo, de tal manera que el mal y el reproche de la pena deben ser mandatos de una iustitia retributiva. En

\footnotetext{
${ }^{1}$ Director del Instituto de Derecho Penal de la Universidad de Bonn, profesor de la materia 2 Acerca del concepto de bien jurídico penal véase Jakobs, Strafrecht AT, 1983, pág. 27 ss. El bien jurídico penal puede interpretarse, a su turno, como un bien jurídico que es protegido mediante la norma de la embriaguez total típica (§ 323a StGB); al respecto véase Kindhäuser, Gefährdung als Straftat, 1989, pág. 325 ss.
} 
otras palabras, la legitimación de la pena se basa en una concepción, racionalmente fundamentable, de la justicia política (criminal).

2. La tesis de la protección indirecta - es decir, mediada por la protección del bien jurídico penal- de bienes jurídicos a través de pena implica suponer que no hay ninguna armonía preestablecida ni mucho menos ninguna identidad entre la norma de sanción, la cual fija las condiciones de punibilidad, y la norma de conducta, la cual sirve a la protección de bienes jurídicos. En este sentido, incluso una acción que conserve un bien jurídico puede, dado el caso, ser punible, tal como lo muestra el siguiente ejemplo. Una esposa tiene planeado darle muerte a su esposo, el cual está enfermo del corazón, administrándole gotas para la tos en lugar de las gotas para el corazón que le han sido medicadas. Sin embargo, en su nerviosismo confunde los medicamentos y le da a su marido las gotas para el corazón que le salvan la vida. Que la esposa es penalmente responsable de tentativa de homicidio (o de tentativa de asesinato) está -de conformidad con el derecho positivo- fuera de toda duda. Pero también está fuera de toda duda que la punibilidad de la conducta no se puede fundamentar por referencia a su carácter dañino para un bien jurídico. Pues la esposa hizo justo aquello que era necesario para la conservación del bien jurídico y que, por esta razón, está mandado para la protección inmediata del mismo.

Si el ejemplo es satisfactorio, entonces la norma de sanción y la norma de conducta deben ser diferentes tanto en su finalidad como en su objetivo. Y la congruencia no puede tampoco establecerse mediante una subjetivización de la norma de conducta. En relación con este último punto se podría decir, por ejemplo, que el objeto materia de la prohibición no sería matar sino querer matar. ${ }^{3}$ Pero entonces la prohibición no sería ya ningún derivado de la protección de bienes jurídicos. Pues incluso una acción que

\footnotetext{
3 Para una concepción tal véase Zielinski, Handlungs- und Erfolgsunwert im Unrechtsbegriff, 1973, pág. 79 ss y passim. Acerca de la circularidad de ese planteamiento veáse v. Kutschera, Grundlagen der Ethik, 1982, pág. 78 ss.
} 
conservara un bien jurídico podría estar prohibida si ella, como en el ejemplo, tuviera una finalidad de lesión.

Por consiguiente, pena y protección de bienes jurídicos están relacionadas la una con la otra solo indirectamente. Mediante la protección de bienes jurídicos se justifican las normas de conducta, las cuales se dirigen a cualquiera o a un círculo específico de destinatarios. Ellas dicen qué formas de conducta están prohibidas y qué formas de conducta están mandadas en razón de ser malas o buenas sub specie protección de bienes jurídicos, respectivamente. A estas normas de conducta se remiten las normas de sanción jurídico penal. Estas últimas establecen en qué medida el destinatario está unido a un "deber" en atención a su "poder", para lo cual informan bajo qué condiciones es contrario a deber y no disculpable ${ }^{4}$ el no haber reconocido la norma de conducta como un motivo vinculante para la acción. ${ }^{5} \mathrm{Y}$ ello ocurre, precisamente, cuando la conducta expresa una desviación considerable del nivel protegido de motivación suficientemente fiel al derecho.

Lo anterior se deja aclarar con el caso ejemplificado atrás. Si la prohibición de matar (o, respectivamente, el mandato de conservar la vida) fuera el motivo dominante de su acción, la esposa debería omitir el darle a su marido gotas para la tos en lugar de gotas para el corazón. Dado que ella prefiere como razón para la acción su motivo -jurídicamente inaceptable- a la norma, expresa así que para ella la prohibición de matar no es vinculante y, con ello, no reconoce - pese a la conformidad objetiva con la norma- la validez de la prohibición de matar. ${ }^{6}$ Aquí no hay ninguna contradicción valorativa entre la norma de conducta y la norma de sanción, pues ambas normas tienen un nivel de referencia diferente. Objeto de la norma de conducta es la valoración de la conducta de la esposa sub specie protección

\footnotetext{
${ }^{4}$ Detallado al respecto Kindhäuser (nota 1), pág. 29 ss.

5 En esta interpretación las normas de conducta son entendidas como razones que obligan a actuar; véase también Raz, Practical Reason and Norm, 1975, pág. 15 ss. La conformación del deber es, por el contrario, asunto de la norma de sanción.

${ }^{6}$ La problemática de la imprudencia en el caso no es aquí de relevancia.
} 
de bienes jurídicos. Objeto de la norma de sanción es la valoración de la motivación sub specie bien jurídico penal.

$\mathrm{Si}$, de conformidad con las reflexiones anteriores, es verdad que el nivel de referencia de la pena no es la protección (inmediata) de bienes jurídicos, sino el reconocimiento de normas de conducta protectoras de bienes jurídicos, entonces cabe preguntar en qué medida puede la pena ofrecer esa garantía de validez.

1. Los problemas que cada teoría de la pena plantea son bien conocidos. ${ }^{7}$ Una teoría de la retribución acorde con el ius talionis y referida al daño al bien jurídico mediante el hecho punible ejecutado debería concluir, en el caso ejemplificado antes, en la no punibilidad de la esposa debido a la ausencia de daño. Por el contrario, las dificultades de las teorías prevencionistas radican en la necesidad de hacer compatible el carácter represivo y reactivo de la pena con un concepto estratégico de la prevención del delito orientado al futuro. La forma recomendable de llevar a cabo esta empresa es atendiendo cada caso concreto, nunca de forma omnicomprensiva pues frente a esta última forma de proceder es fácil construir ejemplos en contra. Así, supóngase que el plan de la esposa tuvo éxito. La prevención especial debería ser aquí prácticamente innecesaria. El caso solo tiene lugar una vez y la autora no está en camino de convertirse en una asesina en serie. La prevención general intimidante debe reconocer, en cualquiera de sus variantes, la propia inefectividad en el caso concreto y, por esta razón, no puede nombrar ninguna razón que explique por qué debería poder funcionar en el futuro frente a constelaciones de casos similares. Además, la prevención general negativa cae bajo la crítica kantiana según la cual ella le roba al autor, quien es utilizado como un medio para un fin, su dignidad

\footnotetext{
${ }^{7}$ Véase, por todos, Naucke, Strafrecht, 5. Ed., 1987, pág. 43 ss.
} 
humana y lo adscribe al derecho de $\operatorname{cosas}^{8}$ Finalmente, la suposición según la cual la pena estabilizaría normas al crear o reforzar fidelidad al derecho, es una suposición elíptica. Pues ella deja abierto en qué forma la pena surte dicho efecto: mediante retribución, mediante prevención especial o mediante intimidación. La teoría de la prevención general positiva no es aún, en esa versión, ninguna teoría de la pena. Pues ella fundamenta indirectamente la protección de bienes jurídicos sin nombrar el medio.

Si resulta exitosa la determinación y la legitimación del medio, y, especialmente, si con ello se logra escapar a la crítica kantiana, entonces la prevención general positiva podría desarrollarse como una teoría penal válida. La prevención general positiva tendría, además, la ventaja de poder integrar tranquilamente los elementos de otras teorías penales que resultaran admisibles. Así, por ejemplo, para ella no resultaría difícil la posibilidad de mostrar el efecto intimidante de la pena -eventualmente imposible de negar- como un efecto colateral útil, aun cuando no constituyente de su legitimación, sin tener por ello que desarrollar un concepto - global pero de cualquier manera incompleto- de la intimidación.

Desde una perspectiva superficial, no obstante, podría parecer ventajoso el formular la prevención general positiva solo de forma elíptica. Dado que de esta manera la prevención general positiva deja abierto de qué forma la pena sirve a la estabilización de la norma -mediante retribución, intimidación, satisfacción del sentimiento de venganza, etc.-, entonces no necesitaría tampoco dar cuenta del medio. Bastaría con remitirse a la estructura policausal de los mecanismos sociales y guardar silencio frente al resto. Pero esto no es correcto, y no lo es por al menos dos motivos de importancia. En primer lugar, porque tiene que haber un criterio para la medición de la pena y, evidentemente, la determinación de dicho rasero dependerá de la interpretación de la pena. Y en segundo lugar, porque la

\footnotetext{
8 Metaphysik der Sitten, 1797, Rechtslehre, parte II, sección 1, anotación general E, A 197, KantStudienausgabe, tomo IV, pág. 453.
} 
fidelidad al derecho solo puede generarse o reforzarse mediante pena cuando la pena es valorada como la reacción correcta. Pero, dado que la corrección de la reacción no puede depender de lo que cualquiera tenga fortuitamente por correcto, sino que debe depender de aquello que de conformidad con el derecho sea tenido por correcto $-\mathrm{y}$ en este sentido la fidelidad al derecho debe ser incluso fomentada-, entonces la pregunta por la corrección debe contestarse obligatoriamente desde el punto de vista del derecho. Por esta razón la teoría de la pena es en un punto, o más exactamente, en el punto más decisivo inmune frente a la ponderación empírica de sus consecuencias.

2. Si la pena debe consolidar y fomentar la fidelidad al derecho, entonces ella debe ser la reacción correcta desde el punto de vista del derecho. Pero, incluso, ella debe ser más que eso, pues la pena presupone que la acción del autor fue deficitaria justo en el momento en el que la fidelidad al derecho se vería disminuida o desaparecería si no existiera la pena como reacción. En un ordenamiento jurídico cuyo criterio de corrección sea la justicia un déficit tal solo puede ser visto como una carencia del sentido de justicia9.

Lo anterior significa que la legitimación de la pena tiene los siguientes presupuestos. El hecho punible debe ser una conducta que permita reconocer una carencia significativa del sentido de justicia. Esta carencia del sentido de justicia debe manifestarse en la utilización, por parte del autor, de una ventaja que va en perjuicio de los co-sujetos y que es, por esta razón, percibida como injusta. Si el uso de esta ventaja permaneciera sin castigo, entonces también debería ser posible para los co-sujetos igual utilización de dicha ventaja. Ahora, dado que un uso tal va en perjuicio de un ordenamiento justo, entonces la ventaja reclamada por el autor debe compensarse (simbólicamente) a título de desaprobación -y esto significa:

\footnotetext{
9 Acerca del sentido de justicia véase Rawls, "The Sense of Justice" en: The Philosophical Review, 1963, pág. 281 ss.
} 
recalcando la carencia del sentido de justicia- mediante la irrogación de una desventaja. Con otras palabras: el autor debe, por esta razón, ser penado.

Con fundamento en estos presupuestos, los cuales deben ser explicados en detalle uno por uno, la pena se interpreta como una retribución con reproche ético jurídico. Sin embargo, y al contrario de lo que ocurre en la teoría de la retribución, el mal denominado como "pena" no es concebido como una respuesta que refleje la contracara de un daño a un bien jurídico responsabilidad del autor. Porque con ese proceder se elige mal el nivel de referencia. El daño que debe ser retribuido tiene que ser, por el contrario, el lado objetivable de la culpabilidad. Y ese lado no es otro que la disminución del valor de reconocimiento de la norma de conducta, disminución que se pone de manifiesto con el hecho punible. Culpabilidad es la mengua de validez experimentada por la norma mediante su -injusto- no reconocimiento. De allí no solo se sigue que la pena tiene que ser adecuada a la culpabilidad, sino también, y justamente, que la pena solo es correcta si ella es adecuada a la culpabilidad.

Mi tesis presupone, entonces, que la culpabilidad es una realidad social que, por añadidura, tiene un tamaño medible. Esta aseveración suena más osada de lo que ella es. Así, también el legislador asume, mediante la creación de marcos punitivos, que la culpabilidad tiene límites hacia arriba y hacia abajo. Ahora, esto solo tiene sentido si la culpabilidad jurídico penal posee un valor negativo en relación con un criterio específico. Este criterio, en el nivel de referencia elegido, es el valor que tiene la validez de una norma: el valor de su reconocimiento. Así, por ejemplo, dado que el valor de reconocimiento de la prohibición de matar figura muy por encima del valor de reconocimiento de la prohibición de hurtar, entonces la culpabilidad del homicida es per se mayor a la del ladrón.

Para conjurar el peligro de circularidad en esta argumentación se necesita una respuesta a la pregunta por el criterio que permita fijar, de forma vinculante, el valor de reconocimiento de la norma y, con ello, una 
respuesta a la pregunta por el criterio de justicia aplicable a las normas de conducta jurídico penal.

3. La determinación del valor de una norma transcurre por tres niveles. En primer lugar, la norma debe estar orientada a fines. En este nivel, entonces, su función de medio se encuentra en un primer plano: la norma debe ser apta para la consecución del fin requerido. En un segundo nivel lo importante es la utilidad pragmático-social de la norma en el sentido del utilitarismo. ${ }^{10}$ En términos utilitaristas deben valorarse aquellos fines para cuya consecución la norma se ha mostrado como un medio adecuado. No obstante, dado que el utilitarismo deja abierta la cuestión de cómo han de distribuirse las utilidades perseguidas, es decir, si solo una minoría, una mayoría o todos sacarán provecho (o deben sacar provecho), es claro que, en principio, existe la posibilidad de que el seguimiento de una norma que solo esté legitimada por su utilidad colectiva no sea ventajosa para todos, y no solo en términos sincrónicos sino también diacrónicos -es decir, a largo plazo-. Prescribirle a un destinatario una conducta no ventajosa en el sentido de renunciar a su libertad en favor de otros y todavía gravarlo con un mal adicional -la pena- en el evento que contravenga la norma es un puro despliegue de poder, más no justicia. La norma solo puede ser justa -y este es el tercer nivel- si su utilidad es distributiva ${ }^{11}$ (en tratándose de delitos especiales debe exigirse una utilidad distributiva para el círculo de destinatarios potenciales).

El principio de utilidad distributiva se ve satisfecho, antes que nada y sin restricciones, por normas que formulan una renuncia a la libertad en razón de la libertad misma. Normas que estén marcadas por el principio de coexistencia de libertad general no solo le brindan a cada quien la ventaja de poder organizarse libremente a sí mismo, siempre y cuando no se inmiscuya en las esferas de libertad de los demás miembros de la comunidad jurídica,

10 Acerca del utilitarismo véase Höffe, "Einleitung“ en: el mismo (Coord.), Einführung in die utilitaristische Ethik, 1975, pág. 7 ss.

${ }^{11} \mathrm{Al}$ respecto véase Höffe, Politische Gerechtigkeit, 1987, pág. 69 ss. 
sino que son también, al mismo tiempo, las condiciones elementales de la propia protección en las relaciones entre humanos -y en perspectiva diacrónica esto vale para la vida en conjunto entre distintas generaciones-. Sin embargo, deducir la protección normativa de libertades básicas del principio de utilidad distributiva solo arroja como ganancia el carácter ventajoso general de la norma, pero no un valor de reconocimiento específico. Pues qué rango le asigna el particular a sus correspondientes libertades básicas es parte de su libertad. Así, es asunto de cada quien preferir la propiedad a la dignidad o la vida a la libertad de religión. En todo caso, ello tampoco constituye ningún problema para la legitimación teórica dado que, si se me permite decirlo con una metáfora, la renuncia recíproca de libertad puede ser representada como un trueque generalizado ${ }^{12}$. Entonces, la fijación concreta del valor de reconocimiento responde a la pregunta por la formación de la opinión política, la cual no tiene porque derivar en violencia en la medida en que las ventajas individuales continúen existiendo en el paquete de libertades básicas. Por ejemplo, aquel que apartándose de la mayoría de sus co-sujetos- valore más el honor que su vida, también ganará en protección al honor mediante su renuncia al homicidio.

Al tomar como base esta posición los bienes jurídicos se dejan definir como aquellas propiedades de personas, cosas o instituciones que sirven al libre desarrollo de cada quien. ${ }^{13}$ Por su parte, la protección de bienes jurídicos está limitada por la orientación a fines, la utilidad prágmaticosocial y la utilidad distributiva de la norma. En particular aquellas normas que no estén impregnadas por el principio de justicia distributiva, sino que, por ejemplo, solo estén fundamentadas en función de su utilidad colectiva, no pueden asegurar su vigencia mediante pena. Puede que eventualmente sea legítimo sancionar también el quebrantamiento de esas normas

12 En esta medida la justicia primaria es la iustitia commutativa; en contra Rawls, A Theory of Justice, 1971, quien presenta la justicia distributiva en primer plano.

${ }^{13}$ Los detalles de esta definición pueden verse en Kindhäuser (nota 1), pág. 137 ss. 
mediante la irrogación de un mal. ${ }^{14}$ Pero no es legítimo asegurar su vigencia mediante pena si el reproche ético jurídico constitutivo de la pena se va a apoyar en una carencia del sentido de justicia.

4. Examínese ahora otro punto de vista. Afirmar que el bien jurídico penal como tal es digno de protección, y ello independientemente de si el reconocimiento defectuoso de la norma conduce a que la finalidad protectora de la norma falle -es decir, si conduce a un daño en el bien jurídico-, es una afirmación que carece de fundamentación. De cualquier manera una fundamentación tal es prácticamente superflua. Pues la norma debe convertirse en realidad y esto solo ocurre si ella es un motivo efectivo para la acción en el marco de la interacción social. La mera conformidad con la norma otorga tan poca seguridad como poca pérdida de validez genera la mera no conformidad. De esta forma, en lo que tiene que ver con la última alternativa, niños y enfermos mentales, por ejemplo, no afectan la validez de la norma, pues ellos -hablando en términos de teoría contractual- no entran en consideración como partes de un contrato social. Aquel que no puede renunciar a su libertad no defrauda cuando destruye libertad.

Pero entonces, ¿en qué consiste esta defraudación que se muestra como una carencia del sentido de justicia y que debe reprocharse ético jurídicamente? La defraudación consiste, formulado en términos plásticos, en actuar como un free rider. Es decir, el autor hace uso de las renuncias de libertad de los otros, sin renunciar él a su parte. De esta forma quiebra el principio de la coexistencia recíproca de libertad, pues este se funda en un mutuo dar y tomar, mientras que aquí el autor toma dos veces. Él se aprovecha, en los términos de la metáfora (free rider), de los aportes de los otros, los cuales le posibilitan la ventaja del viaje $y$, por añadidura, se ahorra su aporte. De esta manera el autor gana doble a costa de los demás, y eso es injusto.

\footnotetext{
14 Aquí radica el significado exacto de "contravención"; véase también al respecto Erik Wolf, Frank-
} FS, II, 1930, pág. 516 ss. 
La pena racional tiene que compensar esa ventaja mediante la irrogación de una desventaja y, al mismo tiempo, tiene que reprochar la carencia de sentido de justicia expresada en el hecho punible. El reproche es ético jurídico porque él tiene como objeto la lesión del mandato fundamental de reconocimiento recíproco de libertades básicas y dicho mandato es previo al derecho positivo. ${ }^{15}$ En este contexto, entonces, la pena racional también pone de manifiesto que la pretensión de doble ventaja no es rentable y refuerza, así, la confianza de los miembros de la comunidad jurídica en la validez de la normas. Si desatender las normas no paga, entonces no se sentirá explotado o estafado aquel que sí las reconozca efectivamente como sus razones para actuar. De esta forma la pena cumple una función integradora en el sentido de la prevención general positiva, y la cumple además de forma legítima, pues mediante justa retribución no se degrada al autor a la condición de medio para un fin. ${ }^{16}$

5. Al principio de este artículo se afirmó que el bien jurídico penal es aquel nivel suficiente de motivación fiel al derecho. Ahora, para finalizar, debe decirse que el reconocimiento de normas de conducta jurídico penal no es algo que deba imponerse a toda costa. Es decir, no toda ausencia de reconocimiento de una norma expresa siempre un déficit de sentido de justicia. Así, puede suceder que el autor no quiera ganar doble con su quebrantamiento, sino simplemente evitar alguna pérdida de importancia.

\footnotetext{
15 Hoerster cree poder fundamentar la pena estatal en términos positivistas y "libres de metafísica", para lo cual se apoya exclusivamente en la salvaguardia de los intereses de un sujeto que decide racionalmente; véase el mismo, Weinberger-FS, 1984, pág. 225 ss. Pero un sujeto que tome sus decisiones de forma completamente racional y que, además, pueda calcular objetivamente sus necesidades (intereses) libre de prejuicios es difícilmente indentificable como un sujeto empírico, de forma tal que bajo el aspecto de la racionalidad normativa se genera un derecho racional bastante activo. Adicionalmente, un enfoque positivista de este cuño está expuesto irremediablemente al open question argument de la metaética analítica: ¿por qué la satisfacción más racional posible de sus propios intereses es un criterio de corrección del derecho? Una respuesta provisional es la siguiente: la fundamentación que se basa en la salvaguardia de intereses racionales presupone ya un derecho a la libre salvaguardia de intereses.

16 Según Kant (nota 7) es legítimo extraer de la pena utilidades para el autor y sus co-ciudadanos. Es solo la punibilidad la que debe estar éticamente fundamentada.
} 
Aquí se ubica la constelación de casos constitutivos del estado de necesidad disculpante. ${ }^{17}$

De conformidad con las reflexiones anteriores, el derecho penal es una institución necesaria, legítima y que debe conservarse, aunque esto último dentro de estrictos límites. El derecho penal es poder, como todo poder es un arma de dos filos y, por esta razón, es también un enemigo potencial de la libertad que debe garantizar. Ahora, demarcar sus límites es algo que solo tendrá éxito si el derecho penal es comprendido como parte de una estrategia de justicia política fundada éticamente. La penalización del quebrantamiento del deber de llevar libros de contabilidad ( $\$ 283 \mathrm{~b}$ StGB) o del porte de vestidos del mismo color que demuestren una convicción política compartida ( $\S 3,28$ VersammlG) pueden nombrarse como ejemplos de la desmesura de una política criminal filosóficamente irreflexiva.

17 Véase también Brandt, "A Utilitarian Theory of Excuses” en: The Philosophical Review, 1969, pág. 337 ss. 